\title{
Transmittance of selected nanostructurized solar glasses designated via relative change in electrical parameters of silicon solar cells
}

\author{
Malgorzata Pociask-Bialy ${ }^{*}$, Kornelia Kalwas \\ Faculty of Mathematics and Natural Sciences, University of Rzeszow \\ Centre for Innovation and Transfer of Natural Sciences and Engineering Knowledge, \\ S.Pigonia 1, 35-959 Rzeszow, Poland
}

\begin{abstract}
Photovoltaics is one of the most promising technologies for electricity production. In the future, photovoltaics could be an effective and safe source of energy.

In this work were present the results of the analysis of a special solar glasses transmissivity coefficient used as protective cover of photovoltaic cell. Antireflective glass due to its unique physical properties eliminate reflections and significantly increasing light transmission. The study of the relative change in the electrical parameters of photovoltaic cells, with and without coats, as open-circuit current $I_{\mathbf{S C}}$ and the maximum power point MPP are presented in this paper. Research were undertaken with using the solar simulator QuickSun130CA, Class AAA+, under Standard Test Conditions.
\end{abstract}

\section{Introduction}

Thanks to the use of nanotechnology and the introduction of morphological changes of the glass surface used in the manufacture of solar glasses, D.A. Glass Company, were achieved extremely high performance light transmittance of samples of solar glasses measured at STC. We able to design transmittance of these solar glasses with use of the solar cell simulator QS130CA, Endeas Oy, Finland.

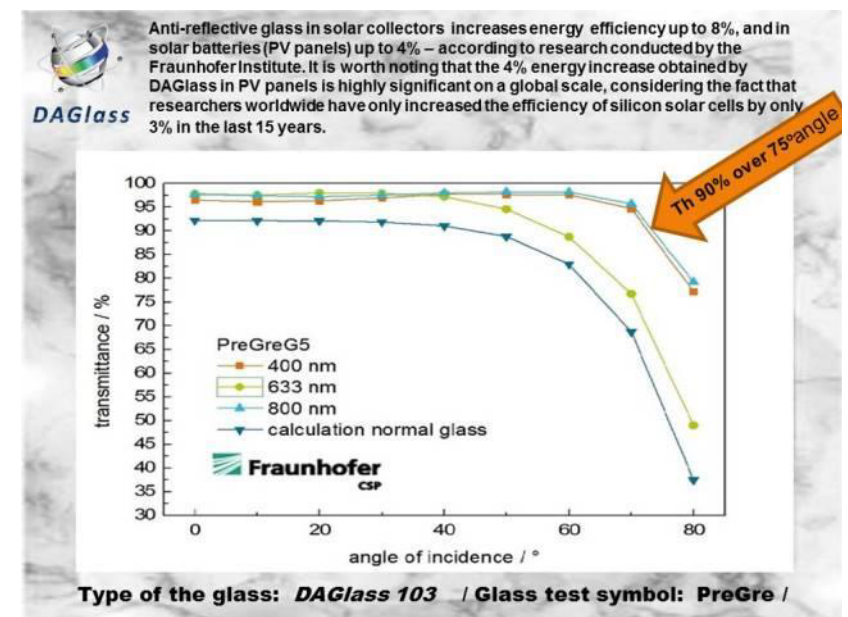

Fig. 1. Increasion of transmittance of DAGlass103 type of glass measured for the angle of incident ray over $75^{\circ}[1]$

D.A. Glass Company products were tested. $T_{d}$ ratio is 99.3\%. The aim performed tests was provided to check the transmissivity of solar glasses samples manufactured at D.A. Glass, which the company set and published on its website. The specific distinguishing feature of the market glasses solar company D.A. Glass is to improve permeability in the range $700-900 \mathrm{~nm}$.

A special product of the company are NSTM AR glasses. Samples are performed via chemical and nanostructurised etching provided to inbuilding into surface structure of solar glasses the micro inclusions similar to short spaghetti. The visible increasing of transmittance DAGlass 103 type of glass is registered for the angle of incident ray over $75^{\circ}$ (see Fig. 1).

\section{Samples and methods}

There were tested six samples of solar glasses, D.A. Glass Company. All measurements were performed on QS130CA solar simulator at Renevable Energy Sources Laboratory of Centre for Innovation and Transfer of Natural Sciences and Engineering Knowledge of University of Rzeszow.

Before calculation we must describe the impact of glass area in the degradation of $\mathrm{I}_{\mathrm{SC}}$ and $\mathrm{P}_{\mathrm{MM}}$ (Fig. 2), the selected parameters of solar cell,when we applied to a cell a solar glass sample. There were measured a group of six different samples. The way how the measurements were performed is presented on Fig. 2 . Using an optical profilometer ContourGT, Bruker (Fig. 3) there were examined the structure of antireflective coatings.

* Corresponding author: pociask@ur.edu.pl 


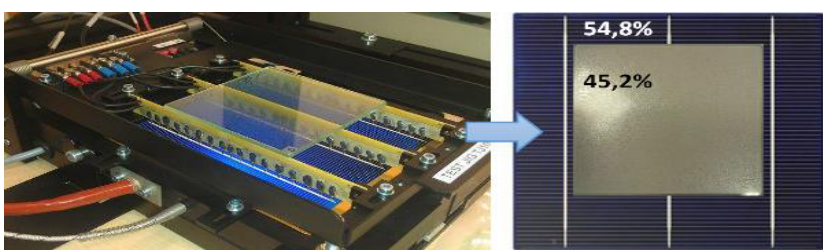

Fig. 2. Solar glass sample placed on referency solar cell. The signal is recorded in $45,2 \%$ from the cell masked by glass, and in $54,8 \%$ from the non masked cell.

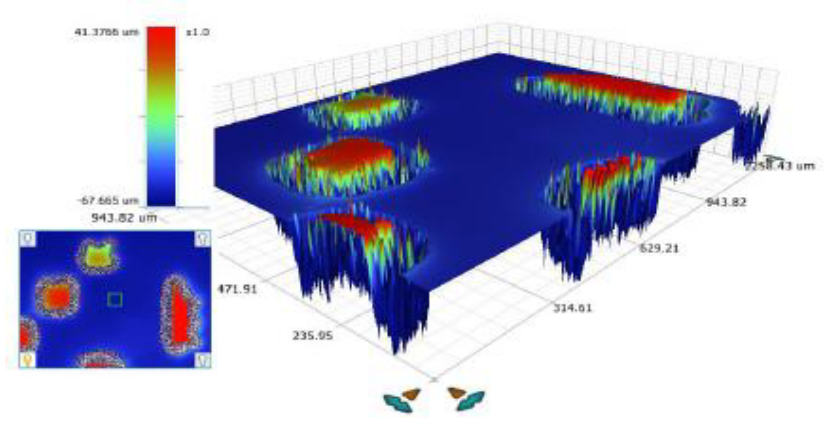

Fig. 3. Results of profile measurements with help of ContourGT, an example for sample No4.

The mean difference between the peak asperities, and the smooth surface of the glass were measured.To measure the density of surface roughness for all samples has been used a Pro HR Dino-Lite microscope. The measured and calculated parameters of all investigated probes are listed in Table 1 . Sample No6 is lack of nanostructurized inclusion.

Table 1. Parameters of solar glasses, specially $\mathrm{S}_{\mathrm{i}} / \mathrm{S}$ - the real surface of solar cell from which the $I=f(U)$ signal was measured.

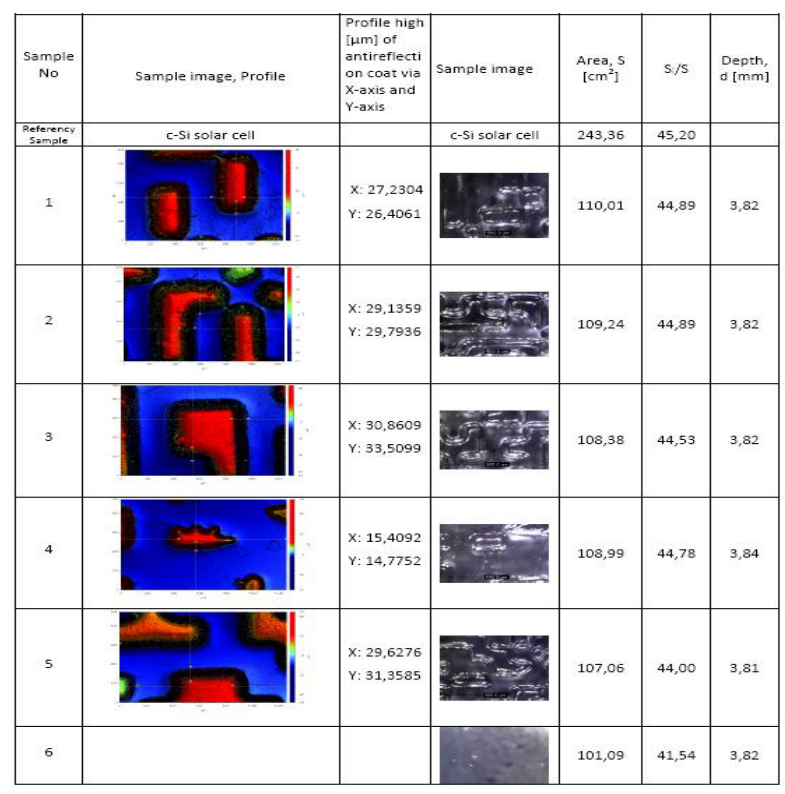

There were measured typical optical parameters of solar glasses like transmittivity $T$ and absorption $A$.
Transmitivity $T$ :

$$
T_{I}=\frac{I_{s c R}}{I_{s c(r e f)}} \cdot 100 \%, \quad T_{P}=\frac{P_{M P R}}{P_{M P(r e f)}} \cdot 100 \%
$$

Real value of open current, $I_{s c R}$ :

$$
\begin{aligned}
I_{S C R}=\left(I_{S c(1,2,3, . .)}\right. & \left.* \frac{S_{(1,2,3, . .)}}{S_{(r e f)}}\right) \\
& +\left(I_{s c(\text { ref })} *\left[1-\frac{S_{(1,2,3, . .)}}{S_{(\text {ref })}}\right]\right)
\end{aligned}
$$

Real value of maximum power, $P_{M P R}$ :

$$
\begin{aligned}
P_{M P R}=\left(P_{M P(1,2,3, . .}\right) & \left.* \frac{S_{(1,2,3, . .)}}{S_{(r e f)}}\right) \\
& +\left(P_{M P(\text { ref })} *\left[1-\frac{S_{(1,2,3, . .)}}{S_{(r e f)}}\right)\right.
\end{aligned}
$$

And transmittancy $T$ described throught both current (fotmula (2)) and power (formula (3)) parameters, as a final result :

$$
T=T \pm\left|T_{I}-T_{P}\right|_{\max }
$$

The absorption coefficient of solar glasses is done clasically:

$$
I_{s c R}=I_{s c(r e f)} e^{-A d}
$$

where $\quad d$-depth of solar glass,

$A$ - absorption coefficient of solar glass.

$$
\frac{I_{S c R}}{I_{s c(\text { ref })}}=e^{-A d}
$$

and optical density $E$ is given by:

$$
\begin{gathered}
\log \frac{I_{s c(r e f)}}{I_{s c R}}=E, \\
E=A d \cdot \log \cdot e=0,4343 \cdot A d \\
A=\frac{E}{0,4343 \cdot d}
\end{gathered}
$$

and

$$
R+A+T=1 .
$$

Our investigations were focused on describing transmittancy $\mathrm{T}$, and reflectivity coefficient $\mathrm{R}$ was only calculated withot any measurements. Our goal was to measure transmittancy $\mathrm{T}$.

The silicon cell operates much worse overlaid by a solar glass. Such a impediment placed on the road incident on cell radiation significantly reduces its performance. Electrical parameters of such setup (Fig. 2) were measured with help of solar simulator QS130CA.

\footnotetext{
Corresponding author:pociask@ur.edu.pl
} 


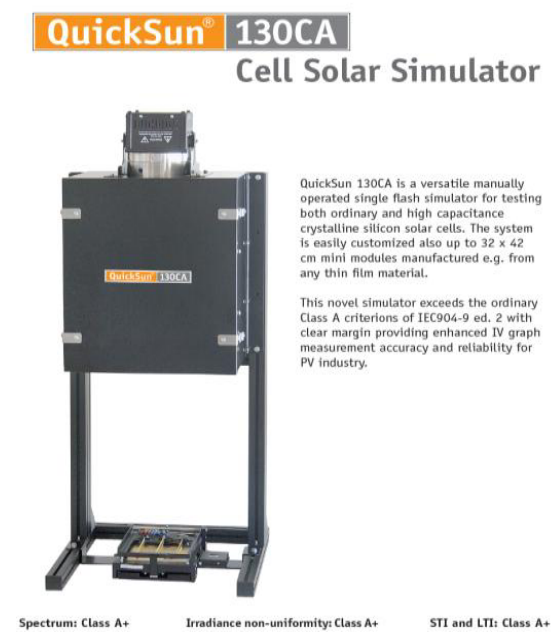

Fig. 4. QuickSun 130CA solar simulator, Endeas Oy, Finland [2].
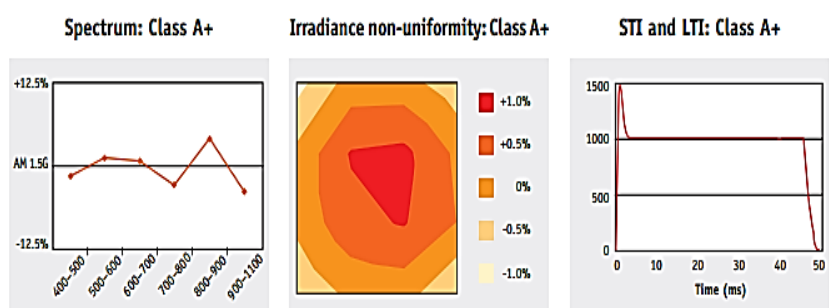

Fig. 5. QuickSun 130CA solar simulator, Endeas Oy, Finland class AAA+ [2].
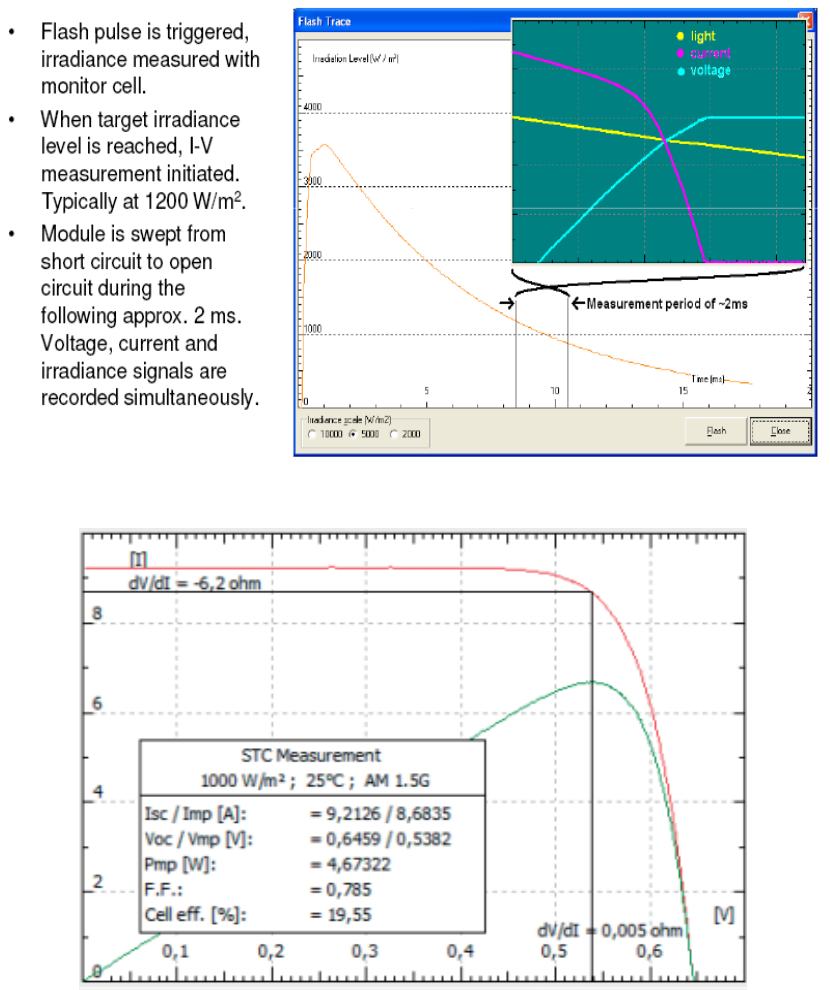

Fig. 6. QuickSun130CA Software. The idea of measurements in brief [2].

\section{Results and discussion}

There were measured both sides of investigated samples: smooth and nanostructurized. Every test was repeated twice, and average value represents a final result of measurements performed on QS130CA solar simulator [3].

In Fig. 7 are presented selected results of tests for sample No 1. There were three curves, each indicates voltage-ampere characteristics: black reference cell signal, red - signal taken from cell and glass from nanostructucturized side, and green signal taken from cell and glass from smooth side.

\section{Ref. cell and Sample No.1, I=f(U)}

U, V - x-axis, I, A - y-axis,

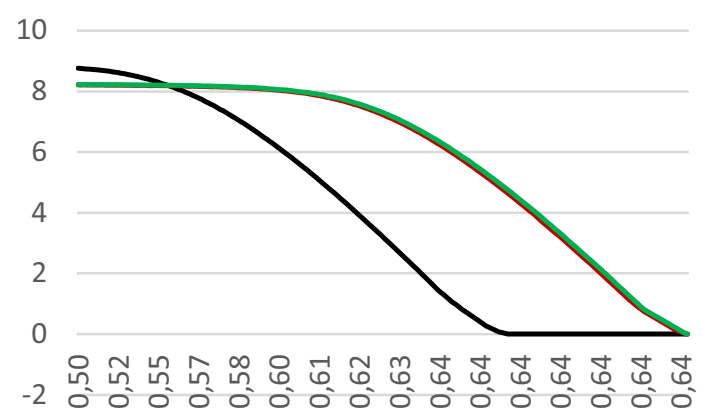

Fig. 7. Results of tests done with help of QS130CA for sample No 1 with certificate of measurements.

\begin{tabular}{|l|l|l|l|}
\hline \multicolumn{2}{|c|}{ STC: $1000 \mathrm{~W} / \mathrm{m}^{2} ; 25^{\circ} \mathrm{C} ;$ AM 1.5G Sample No. 1 } \\
\hline Parameter & Ref. cell & nanostruct. & smooth \\
\hline Isc [A] & 8,945 & 8,254 & 8,253 \\
\hline Voc [V] & 0,643 & 0,642 & 0,642 \\
\hline Pmp [W] & 4,55 & 4,19 & 4,20 \\
\hline F.F. [\%] & 79,063 & 79,173 & 79,16 \\
\hline Cell eff. [\%] & 18,7 & 17,233 & 17,237 \\
\hline
\end{tabular}

In Tables 2-6 are presented results of measurements and calculations.

Table 2. Electrical parameters of tested solar cell with coating the investigated samples of solar glasses taken from nanostructurized side and from smooth side.

\begin{tabular}{|c|c|c|c|c|c|}
\hline & $\begin{array}{l}\text { Sample, No; } \\
\text { analysed side }\end{array}$ & $\begin{array}{l}\mathrm{I}_{\mathrm{sc}} \\
{[\mathrm{A}]}\end{array}$ & $\begin{array}{l}V_{o c} \\
{[V]}\end{array}$ & $\begin{array}{l}P_{m p} \\
{[W]}\end{array}$ & $\begin{array}{l}\mathrm{FF} \\
{[\%]}\end{array}$ \\
\hline \multirow{3}{*}{ 1: } & ref. cell & 8,945 & 0,643 & 4,55 & 79,06 \\
\hline & nanostruct. & 8,254 & 0,642 & 4,19 & 79,17 \\
\hline & smooth & 8,253 & 0,642 & 4,20 & 79,16 \\
\hline \multirow[t]{2}{*}{ 2: } & nanostruct. & 8,238 & 0,642 & 4,187 & 79,15 \\
\hline & smooth & 8,262 & 0,642 & 4,20 & 79,13 \\
\hline \multirow[t]{2}{*}{ 3: } & nanostruct. & 8,263 & 0,642 & 4,20 & 79,14 \\
\hline & smooth & 8,266 & 0,642 & 4,20 & 79,10 \\
\hline \multirow[t]{2}{*}{ 4: } & nanostruct. & 8,276 & 0,642 & 4,20 & 79,18 \\
\hline & smooth & 8,277 & 0,642 & 4,21 & 79,16 \\
\hline \multirow[t]{3}{*}{ 5: } & nanostruct. & 8,275 & 0,642 & 4,21 & 79,24 \\
\hline & smooth & 8,274 & 0,642 & 4,21 & 79,21 \\
\hline & smooth/smooth & 8,476 & 0,642 & 4,21 & 79,10 \\
\hline
\end{tabular}

\footnotetext{
Corresponding author:pociask@ur.edu.pl
} 
Table 3. Relative displacement voltage in the current voltage curves $\Delta$ Uoc. Electrical parameters of tested solar cell with coating the investigated samples of solar glasses taken from nanostructurized side and from smooth side.

\begin{tabular}{|c|c|c|c|c|}
\hline Sample & I [A] & $\begin{array}{l}\text { Uoc_nanost. } \\
\text { [V] }\end{array}$ & $\begin{array}{l}\text { Uoc_smooth } \\
\text { [V] }\end{array}$ & $\Delta \mathrm{Uoc}$ \\
\hline \multirow{3}{*}{ í } & 0,5 & 0,63899 & 0,63933 & $-0,00034$ \\
\hline & 2 & 0,62997 & 0,63071 & $-0,00101$ \\
\hline & 4 & 0,61468 & 0,61593 & $-0,00125$ \\
\hline \multirow{3}{*}{$\begin{array}{l}\sim \\
\dot{0}\end{array}$} & 0,5 & 0,63909 & 0,63806 & 0,00103 \\
\hline & 2 & 0,62940 & 0,62800 & 0,0014 \\
\hline & 4 & 0,61480 & 0,61327 & 0,00153 \\
\hline \multirow{3}{*}{$\begin{array}{l}m \\
\dot{0}\end{array}$} & 0,5 & 0,63905 & 0,63870 & 0,00035 \\
\hline & 2 & 0,63010 & 0,62941 & 0,00069 \\
\hline & 4 & 0,61484 & 0,61410 & 0,00074 \\
\hline \multirow{3}{*}{$\begin{array}{l}\dot{ } \\
\dot{2}\end{array}$} & 0,5 & 0,63947 & 0,63798 & 0,00149 \\
\hline & 2 & 0,63011 & 0,62837 & 0,00174 \\
\hline & 4 & 0,61534 & 0,61309 & 0,00225 \\
\hline \multirow[t]{3}{*}{$\begin{array}{l}\text { un } \\
\dot{0}\end{array}$} & 0,5 & 0,63914 & 0,63914 & 0 \\
\hline & 2 & 0,62914 & 0,62954 & $-0,00040$ \\
\hline & 4 & 0,61548 & 0,61464 & 0,00084 \\
\hline
\end{tabular}

Table 4. Transmittivity of investigated solar glasses samples for measurements taken from smooth side of sample.

\begin{tabular}{|l|c|c|}
\hline $\begin{array}{l}\text { Sample, No ; } \\
\text { smooth side }\end{array}$ & $T_{I}=\frac{I_{S C R(1,2,3, . .)}}{I_{S C R(r e f)}}[\%]$ & $T_{P}=\frac{P_{M P R(1,2,3, . .)}}{P_{M P R(r e f)}}[\%]$ \\
\hline ref. cell: & 100,00 & 100,00 \\
1: & $96,50 \pm 0,02$ & $96,52 \pm 0,02$ \\
2: & $96,57 \pm 0,03$ & $96,55 \pm 0,03$ \\
3: & $96,62 \pm 0,05$ & $96,57 \pm 0,05$ \\
4: & $96,66 \pm 0,01$ & $96,65 \pm 0,01$ \\
5: & $96,70 \pm 0,01$ & $96,69 \pm 0,01$ \\
6: & $97,82 \pm 0,93$ & $96,90 \pm 0,93$ \\
\hline
\end{tabular}

Table 5. Transmittivity of investigated solar glasses samples for measurements taken from nanostructurized side of sample.

\begin{tabular}{|c|c|c|c|}
\hline $\begin{array}{l}\text { nanost. } \\
\text { side }\end{array}$ & $\begin{array}{c}\mathrm{g}= \\
\frac{S_{\text {incl. }}}{S_{\text {sample }}},[\%]\end{array}$ & $\begin{array}{c}T_{I}= \\
\frac{\left.I_{S C R(1,2,3, \ldots)}\right)}{I_{S C R(r e f)}}[\%] \\
\end{array}$ & $\begin{array}{c}T_{P}= \\
\frac{P_{M P R(1,2,3, n)}}{P_{M P R(r e f)}}[\%]\end{array}$ \\
\hline ref. cell & - & 100,00 & 100,00 \\
\hline 1: & 39 & $96,51 \pm 0,09$ & $96,42 \pm 0,09$ \\
\hline 2: & 73 & $96,45 \pm 0,04$ & $96,42 \pm 0,04$ \\
\hline 3: & 63 & $96,60 \pm 0,03$ & $96,57 \pm 0,03$ \\
\hline 4: & 28 & $96,65 \pm 0,10$ & $96,56 \pm 0,10$ \\
\hline 5: & 62 & $96,70 \pm 0,02$ & $96,69 \pm 0,02$ \\
\hline $6:$ & 0 & $97,82 \pm 0,93$ & $96,90 \pm 0,93$ \\
\hline
\end{tabular}

Table 6. Absorption coefficient and calculated from formula (10) reflectivity coefficient $\mathrm{R}$.

\begin{tabular}{|ll|l|l|l|l|}
\hline $\begin{array}{l}\text { Sample No ; } \\
\text { analysed side }\end{array}$ & $\begin{array}{l}\mathrm{Al}_{\text {SCR }} \\
{[\%]}\end{array}$ & $\begin{array}{l}\mathrm{AP}_{\text {MPR }} \\
{[\%]}\end{array}$ & $\begin{array}{l}\mathrm{RI}_{\mathrm{SCR}} \\
{[\%]}\end{array}$ & $\begin{array}{l}\mathrm{RP}_{\text {MPR }} \\
{[\%]}\end{array}$ \\
\hline 1: & ref. cell & 0 & 0 & 0 & 0 \\
& nanostruct. & 0,93 & 0,95 & 2,56 & 2,63 \\
2: & smooth & 0,93 & 0,93 & 2,57 & 2,55 \\
& nanostruct. & 0,95 & 0,95 & 2,60 & 2,63 \\
3: & smooth & 0,91 & 0,92 & 2,52 & 2,53 \\
& nanostruct. & 0,90 & 0,91 & 2,50 & 2,52 \\
4: & smooth & 0,90 & 0,91 & 2,48 & 2,52 \\
& nanostruct. & 0,89 & 0,91 & 2,46 & 2,53 \\
5: & smooth & 0,89 & 0,89 & 2,45 & 2,46 \\
& nanostruct. & 0,88 & 0,88 & 2,42 & 2,43 \\
& smooth & 0,88 & 0,88 & 2,42 & 2,43 \\
6: & smooth/smooth & 0,58 & 0,83 & 1,60 & 2,27 \\
\hline
\end{tabular}

Positive offset values indicate that higher light transmittance shows a rough surface solar glass (with a reflective coating), sometimes we observed greater transmissivity of the smooth side of the sample (Table 3 and Table 4). From certificate of sample done on QS130CA the differencies in Uoc between nanostructutized and smooth side of glasses $\Delta \mathrm{Uoc}$ is not visible (Table 2), but if we describe such differencies for different currents, we can see visible changes (Table 3). The biggest difference in voltage values estimated for the sample No. 4, the smallest - for the sample No. 5 (Table 3). All samples (except on the sample No.1) have a higher transmissivity for the roughened side of the glass (Table 5). Sample No.1 is the only one that has a superior transmission properties of the smooth surface of the sample than the nanostructuryzed surface.

We can noticed that the lower the density of the surface nanostructurized roughness (and absorption coefficient, Table 6), the higher the relative transmissivity of the glass (Table 5). The lower the height of the roughness (Table 1) the higher relative transmissivity of glass (Table 5).

The smaller the surface density and the smaller the roughness height the greater the measured voltage differences between smooth and rough surface of the glass. For all samples except sample 1, the antireflection layer exhibits a significantly better transmissivity (Table 5).

Contribution of reflection and absorption coefficient is $3.6 \%$ (Table 6), but the manufacturer's data shows that it is $0.7 \%$.

The values of reflectance and transmittance should be treated as estimates, because they were measured without any integrating sphere. 


\section{Conclusions}

The relative changes in electrical solar cell parameters (short-circuit current, maximum power), it sets the relative transmissivity of solar glasses, are able to provide a test of quality of solar glasses.

From the information provided by D.A. Glass: the solar transmittance of glass is the best at range $60^{\circ}$ $80^{\circ}$ of angles of incidence of solar radiation. With help of QS130CA measurement were done with perpendicular angle of irradiation, and sample No. 6 for that reason (both smooth sides ) is the best for such tests. It should be emphasized the role and importance of experimentally determined relative displacement voltage in the current - voltage curves.Transmissivity coefficient measured via presented way was acheved $96,7 \%$ for nanostructurized side of sample No.5. Our method shows that the best transmittancy has sample No.6 (without absorption coat), for perpendicular incidence of light to the test element.

\section{References}

1. www.daglass.pl/produkty/szklo-dekoracyjne

2. www.endeas.fi/download/QuickSun130CA.pdf

3. Kornelia Kalwas, METHODS FOR DETERMINATION OF TRANSMISSIVITY OF SELECTED MATERIALS USED AS PV ELEMENTS PROTECTIVE COVER, Faculty of Mathematics and Natural Sciences, University of Rzeszow, Rzeszow 2015, MSc thesis, under the supervisior of dr hab. prof. UR Malgorzata Pociask-Bialy 